\title{
Intellectual Grid Modulation and Monitoring
}

\author{
A. B. Abubakirov ${ }^{\text {a }}$, R.J.Tanatarovb, T.U.Kurbaniyazov ${ }^{c}$ and Sh.B.Kuatovad $^{\text {d }}$ \\ A, b, c, d \\ Department of Electrical engineering and metrology, Karakalpak State University, \\ Uzbekistan
}

Article History: Received: 11 January 2021; Accepted: 27 February 2021; Published online: 5 April 2021

\begin{abstract}
In this article design of communicational devices and approbation of Intellectual Grid technologies are considered. As well the characteristics of the functional properties of Intellectual Grid technology are presented. Model of the electrical enginering system in complex program MATLAB (Simulink) are developed.
\end{abstract}

Keywords: Monitoring, Intellectual, Energy supply, Determined, MATLAB (Simulink), asymmetrical, network systems, modulation.

\section{Introduction}

Energy supply systems on the modern aspect of the development of engineering and technology are considered as the Internet, an infrastructure designed to support energy, information, economic and financial relationships between all entities involved in the production, transportation and consumption of all types of energy. The main tasks in the modernization of energy supply networks should be the use of modern technologies in the creation of new sources of capacity, the widespread introduction of renewable energy sources and information-measuring and communication systems and devices. The models, technologies and devices of the Smart Grid system studied in this work serve as basic scientific and practical materials for increasing the efficiency of energy use.

\section{2.. Statement of a Problem}

In general, the Smart Grid concept implies the widespread use of devices, digital technologies and communication networks to collect and process production and consumption data in order to increase the efficiency and reliability of energy supply. These are not only technological changes, but also fundamental ones: decentralization of the system, blurring of the separation between energy consumption and production, a new approach to energy consumption, requiring the following characteristics [1]:

- ability to manage the work of energy consumers;

- self-recovery after abnormal conditions;

- security from physical and cybernetic external interference;

- ensuring energy supply of the required quality;

- synchronous operation of energy storage sources and centers;

- the ability to significantly increase the efficiency of the energy system as a whole.

\section{Main Part}

Smart energy supply is a modern and modernized energy supply that uses informational and communicational networks, devices and technologies to collect information on energy production and consumption, which can automatically increase efficiency, reliability, economic benefits, as well as the sustainability of energy production and distribution. The "Intelligent Energy Supply Network" is a one-piece automated mechanism uniting energy producers, networks and consumers. This mechanism is controlled centrally - through a computer center, which receives information about the level of energy consumption from millions of digital controllers in real time. Specialized software helps to track the operation of all participants in the process of generation, transmission and consumption of electricity. To increase energy efficiency, it is necessary to take a course on the use of renewable energy sources. Andespecially the Smart Grid system is the benchmark for increasing the efficiency of energy use. Special primary measuring devices transform information on the production and consumption of electricity, which allows you to correctly distribute energy resources, to ensure the reliability of their consumption and efficiency of use [2-5].

Smart Grid involves combining a security system with information-measuring functions.

Microprocessor devices based on protection measure currents and voltage in vector form, accumulate data on trips and emergency conditions in special memory blocks. Thus, the protection turns into a kind of information processing center, an element of the diagnostic system and monitoring of power equipment [3-8].

As you can see, the construction of smart grids named "Smart Grid" in the energy sector is perspective and demanding. Today; this is a natural stage in the development of the global economy and social relations. In practice, the authors of this work are actively working on the development and design of info communicational devices and approbation of Smart Grid technologies; the prospects for their development which can be formulated in a larger way by a histogram as shown in fig.1: 
The development of renewable energy sources with their further inclusion in a single energy system is a strategically important task.

Development of distributed energy to cover maximum loads and eliminate energy shortages is a very important task for the distribution energy network complex.

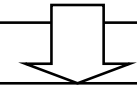

Ensuring uninterrupted operation of the energy system in the context of an increase in the number and capacity of energy consumers.

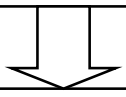

Reduction of energy losses due to the construction of intelligent metering systems with the ability to take into account energy quality and limit energy loads.

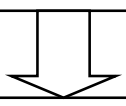

Development of a communication environment, devices and systems capable of reliably and efficiently supporting bi-directional information exchange between sources and consumers of energy resources. One way to solve this problem is to use wireless intelligent communication devices.

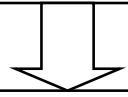

Improving the quality of energy through the use of devices and technology for reactive power compensation.

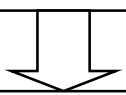

The use of intelligent equipment and software systems for managing parameters and quantities of energy supply in order to ensure reliable operation.

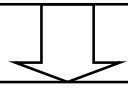

The use of high-capacity energy storage devices to align the energy load schedule, as well as to ensure uninterrupted operation of energy supply facilities.

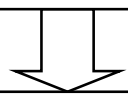

Development of market relations in the energy business with the involvement of energy consumers (the creation of separate energy supply areas - an analogue of Microgrids) as possible energy suppliers at the right time to the right energy supply areas.

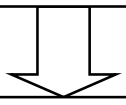

Development and production of high-tech competitive devices to ensure the functioning of the smart grid.

The listed aspects of the future intellectual energy network clearly correspond to the modernization scenario of energy supply

development. As part of this study, the key requirements for the developed Smart Grid system are formulated in tab.1.

Key requirements

Tab. 1.

providing consumers with energy without restrictions,

depending on when and where they need it, and

Availability

depending on the amount paid 
the ability to withstand physical and informational

negative influences without total outages or high costs

of restoration work, the fastest recovery (self-

Reliability

optimization of tariffs for electric energy for consumers and reduction of system-wide costs

Profitability

maximizing the efficiency of use of all types of

resources, technologies and equipment in the production, transmission, distribution and

interaction with the environment - the maximum possible reduction in negative environmental impacts

prevention of situations in the electric power industry

that are dangerous for people and the environment

Efficiency

Organic

Security

Power Supply Reliability

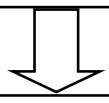

The emergence of advanced technologies as a result of scientific and technical progress, which did not find proper application in modern Smart Grid

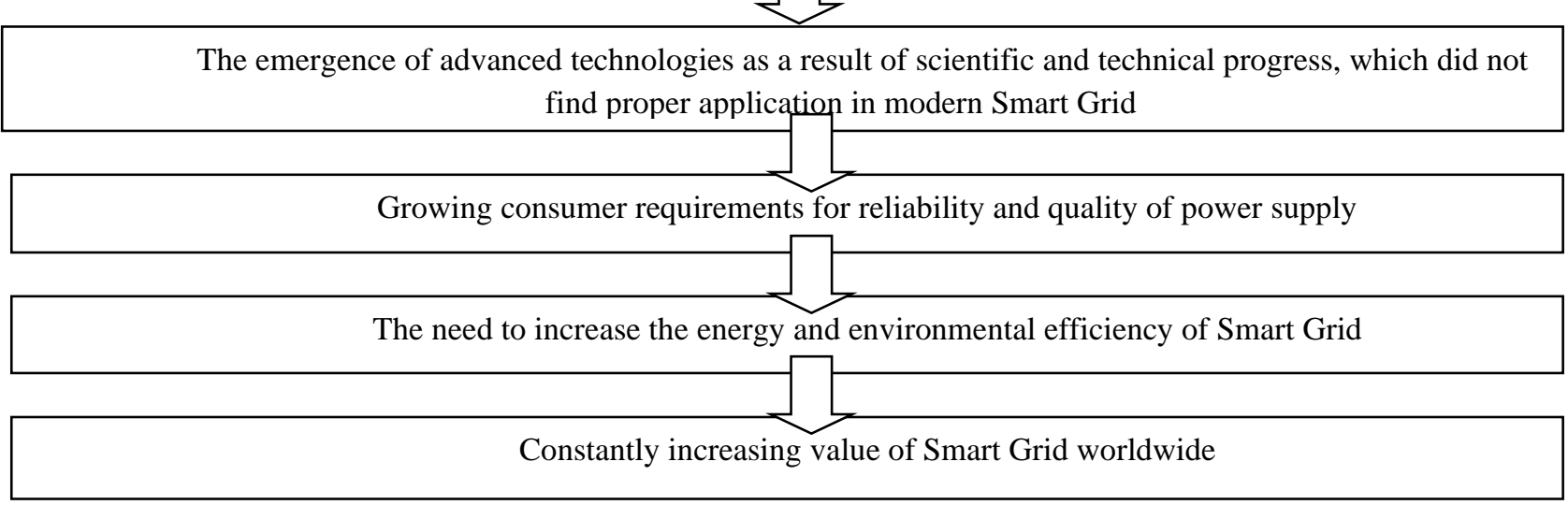

Fig. 2 The main factors of determining the development of Smart Grid.

The Characteristics of the functional properties of Smart Grid Technology are formulated in tab.2.

Tab. 2.

\begin{tabular}{|l|l|}
\hline Existing energy supply system & Smart Grid-based energy supply system \\
\hline $\begin{array}{c}\text { One-way communication between elements or } \\
\text { absence }\end{array}$ & Two way communication \\
\hline $\begin{array}{c}\text { Centralized Generation - Complex Integrated } \\
\text { Distributed Generation }\end{array}$ & Distributed generation \\
\hline The topology is predominantly radial & Mostly network \\
\hline Accident response & Accident Prevention Response \\
\hline Work equipment to failure & $\begin{array}{l}\text { Monitoring and self-diagnosis, prolonging the } \\
\text { "life" of equipment }\end{array}$ \\
\hline Manual recovery & Auto Recovery - Self-healing Networks \\
\hline System crash susceptibility & Systemic accident prevention \\
\hline Manual and fixed network allocation & Adaptive highlighting \\
\hline On-site inspection of equipment & Remote equipment monitoring \\
\hline Limited power flow control & Power Flow Management \\
\hline $\begin{array}{l}\text { Inaccessible or very late price information for } \\
\text { the consumer }\end{array}$ & Real time price \\
\hline
\end{tabular}


The results of modeling and research parameters combined control system of sources of reactive power of Smart Grid on base of the complex of the programs MATLAB is presented in fig. 3 and 4. The model of control of source of reactive power was determined that designed model in real scale of time allows to define the parameters and values element of Smart Grid energy system.

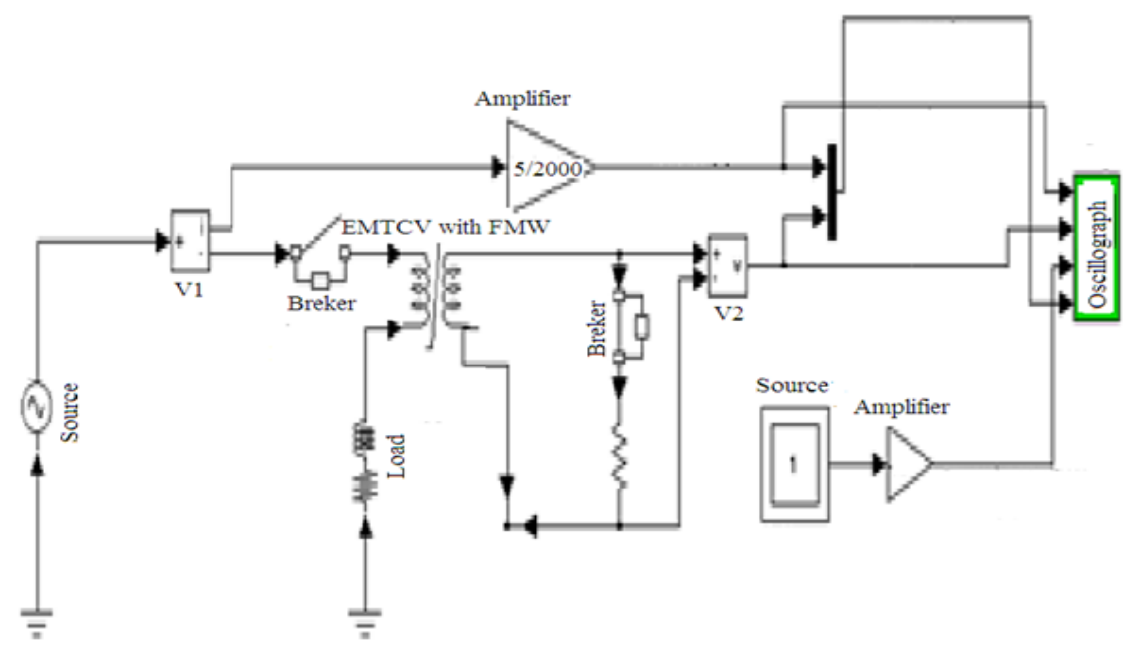

Fig. 3. Model of the research part of power system in complex program MATLAB.

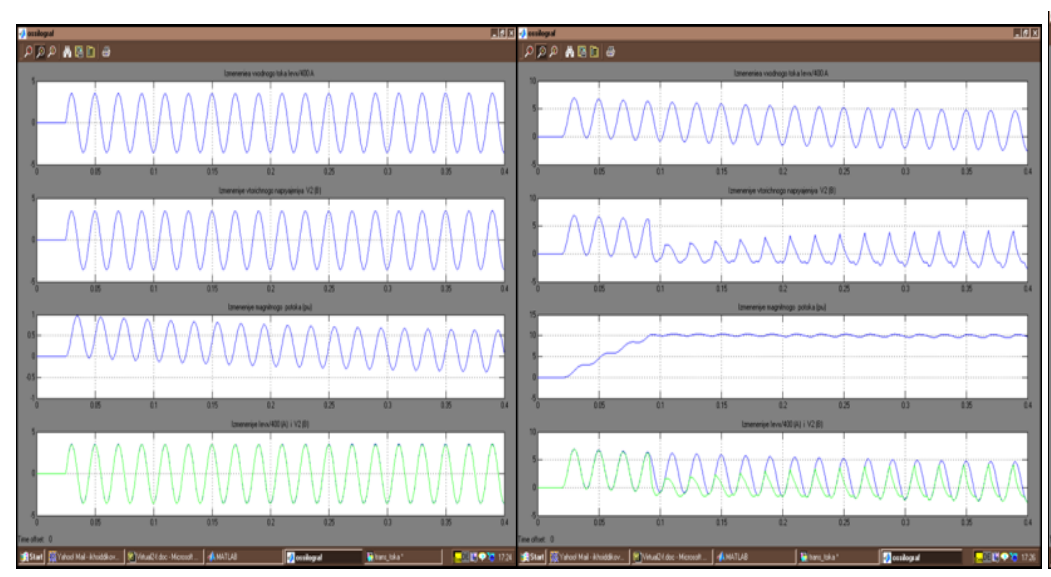

a)

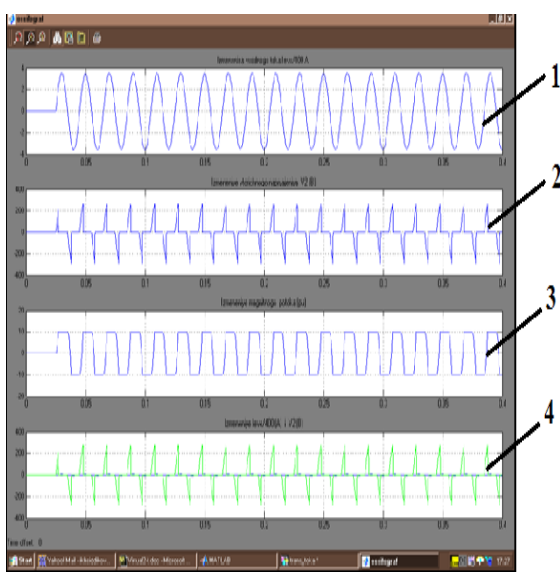

c)

Fig.4. Graphics of input (1 - a primary current - Ie in), intermediate (2 - m.m.p. F1 and 3- magnetic flow - F2) and output (4 - a secondary voltage Ue out) of the values of voltage under: normal (a), asymmetrical (b) mode and in mode of the short circuit (c) in electric networks of of Smart Grid energy system.

As can be seen from the results of modeling and research based on the complex program MATLAB, connecting processes i.e. change the output voltage of are fixed through $0,044 \mathrm{~s}$. after enabling the electric load in current wire of the electric nets of Smart Grid energy system.

\section{Conclusion}

In given paper described methods and technological aspects of design of power supply systems and nets of intellectual grid and equipment's of control values and parameters of communication nets and power supply systems, analyzed: principles of design of power systems on the bases of Intellectual Grid; problems of research and design; allowed solve a problem development and construction efficient power systems. Used automatically controlled of the sources of reactive power in electric sets and power devices with nominal power $50 \mathrm{kVt}$ and voltage till $500 \mathrm{kV}$, allowed increasing of capacity power equipment and energy, resource saving in elements of control voltage of the power supply of control system of Intellectual Grid.

\section{Reference}

1. I.Kh.Siddikov, M.A.Anarbaev, A.A.Abdumalikov, A.B.Abubakirov, M.T.Maxsudov, I.M.Xonturaev. «Modelling of transducers of nonsymmetrical signals of electrical nets» // International Conference On Information Science And Communications Technologies Applications, Trends And Opportunities

2. // Publication Year: 2019, Page(s): 1-6. http://WWW.ICISCT2019.Org

3. I.X.Siddikov, A.B.Abubakirov, A.J.Allanazarova, R.M.Tanatarov, Sh.B.Kuatova // Modeling the secondary strengthening process and the sensor of multiphase primary currents of reactive power of renewable electro energy supply // Solid State Technology, Volume: 63 Issue: 6, Publication Year: 2020, pp: 13143-13148. 
4. Abubakirov A.B., Yo'ldashev A.A., Baymuratov I.Q., Sharipov M.T., Utemisov A.D. «Study of conversion circuits and design of the electromagnetic primary current and voltage transducer of monitoring and control systems» // EPRA International Journal of Research and Development. Volume: 5 India. 2020. - C. 214-218. (SJIF Impact Factor: 6.260| ISI I.F.Value:1.241| Journal DOI: 10.36713/epra2016 ISSN: 2455-7838(Online)).

5. Siddikov I., SattarovKh.,Khujamatov H. Modeling of the Transformation Elements of Power Sources Control// 2017 International Conference on Information Science and Communications Technologies (ICISCT), November, 2017, Tashkent, Session 5. https://www.tuit.uz/en/post/ilmiyanjuman.

6. Petrova I., Zaripova V, Lejnina Yu., Siddikov I.Automated system for synthesis of sensors for smart cities. xxii international scientific conference on advanced in civil engineering "construction the formation of living environment' Tashkent, Uzbekistan, 18-21 April, 2019https://www.scopus.com/record/display.uri?eid=2-s2.0-85067281218\&origin=resultslist

7. ZaripovM.F. PetrovaI.Y. Предметно-ориентированная среда для поиска новых технических решений «Интеллект»// ІВ Санкт-Петербургская международная конф. «РИ-95»: Тез. докл. - Спб., 1995. - C. 60-61.

8. Zaripov M.F. Zaynullin N.R., PetrovI.Y..Графовой метод научно-технического творчества. - М.: ВНИИПИ ГКНТ, 1988. - 124 с.

9. Lukashkin V.G., Garipov V.K. Sleptcov V.V., Matei Visniec A.V., Вишнеков А.В. Автоматизация измерений, контроля и управления. - М.:Машиностроение, 2005.- 663 с. 